Corrigendum

\title{
Corrigendum to "Eel's Head Powder Reduces Mild-Moderate Depression in Geriatric Individual: Result from Randomized Controlled Trial Study"
}

\author{
Karina Shasri Anastasya $\mathbb{D}^{1},{ }^{1}$ Shelly Iskandar $\mathbb{D}^{2}{ }^{2}$ Dewi Marhaeni Diah Herawati $\mathbb{D},^{3}$ \\ and Nur Atik ${ }^{4}{ }^{4}$ \\ ${ }^{1}$ Graduate School of Biomedical Sciences Master Program, Faculty of Medicine, Universitas Padjadjaran, Bandung, Indonesia \\ ${ }^{2}$ Department of Psychiatry, Faculty of Medicine, Universitas Padjadjaran/Hasan Sadikin Hospital, Bandung, Indonesia \\ ${ }^{3}$ Department of Public Health, Faculty of Medicine, Universitas Padjadjaran, Bandung, Indonesia \\ ${ }^{4}$ Department of Biomedical Sciences, Faculty of Medicine, Universitas Padjadjaran, Bandung, Indonesia
}

Correspondence should be addressed to Nur Atik; n.atik@unpad.ac.id

Received 16 December 2020; Accepted 16 December 2020; Published 18 January 2021

Copyright ( 92021 Karina Shasri Anastasya et al. This is an open access article distributed under the Creative Commons Attribution License, which permits unrestricted use, distribution, and reproduction in any medium, provided the original work is properly cited.

In the article titled "Eel's Head Powder Reduces MildModerate Depression in Geriatric Individual: Result from Randomized Controlled Trial Study" [1], there was an error in the Materials and Methods section. In Section 2.1, Eel Powder Production, "Pelabuhanratu, Sukabumi, West Java, Indonesia," should be corrected to "Banyuwangi, East Java, Indonesia." Dr. Dewi Marhaeni was previously acknowledged in the acknowledgements statement. However, due to author miscommunication, she should have been listed as an author. The corrected author list is shown above. The authors apologize for these mistakes.

\section{References}

[1] K. S. Anastasya, S. Iskandar, and A. Nur, "Eel's head powder reduces mild-moderate depression in geriatric individual: result from randomized controlled trial study," Evidence-Based Complementary and Alternative Medicine, vol. 2020, Article ID 4658514, 5 pages, 2020. 